\begin{tabular}{lllll}
\hline Motrivivência & Ano XX, & No 30, P. 128-142 Jun./2008 \\
\hline
\end{tabular}

\title{
Linha de Estudos Epistemológicos e Didáticos em Educação Física Escolar - LEEDEFE: o compromisso com a relação entre epistemologia e prática pedagógica
}

\author{
Line Epistemological Studies and Didactical \\ Physical Education in School - LEEDEFE: the \\ compromise with the relationship between \\ epistemology in practice pedagogical
}

\author{
Ecléa Vanessa Canei Baccin' \\ Vilmar José Both² \\ Maristela da Silva Souza ${ }^{3}$
}

\begin{abstract}
Resumo Abstract
Esse trabalho busca apresentar o compromisso da Linha de Estudos

Epistemológicos e Didáticos em Educação Física Escolar (LEEDEFE) com a relação entre epistemologia e prática pedagógica. Para tanto, fazemos um relato da construção
\end{abstract}

1 Graduada em Educação Física pela Universidade Federal de Santa Maria; Especialista em Educação Física Escolar pela mesma instituição e atualmente mestranda em Educação Física pela Universidade Federal de Pelotas/RS. Contato: eclea17@yahoo.com.br

2 Graduado em Educação Física pela Universidade Federal de Santa Maria; Especialista em Educação Física Escolar pela mesma instituição e atualmente mestrando em Educação Física pela Universidade Federal de Pelotas/RS. Contato: vilmarboth@yahoo.com.br

3 Professora doutora do Departamento de Desportos Individuais do Centro de Educação Física e Desportos da Universidade Federal de Santa Maria. Contato: souzamaris@bol.com.br 
e organização da LEEDEFE, apresentando sua base teórica e atividades que realiza no âmbito do tripé ensino-pesquisa-extensão, visando demonstrar nossas concepções, e, nosso posicionamento na relação universidade-sociedade.

A partir disso, realizamos uma discussão acerca da Educação

Física e da Epistemologia, com base em autores dessas áreas, e, como síntese, defendemos a importante relação entre epistemologia e prática pedagógica, entendendo que essa

relação auxilia os professores a superarem a imediaticidade cotidiana qualificando sua prática pedagógica.

PALAVRAS-CHAVE: Epistemologia Prática Pedagógica - Escola

\section{Introdução}

O presente artigo discorre sobre o compromisso da Linha de Estudos Epistemológicos e Didáticos em Educação Física Escolar - LEEDEFE - com a relação entre epistemologia e prática pedagógica. Para isso, faz-se necessário trazer ao conhecimento de todas as intenções teóricas-metodológicas desta linha, bem como seus objetivos.

A LEEDEFE iniciou suas atividades, oficialmente, no Centro de Educação Física e Desportos (CEFD) da Universidade Federal de and organization of LEEDEFE, presenting its theoretical basis and activities that performs under the tripod teaching-research-extension, to show our conceptions, and our position in society-university relationship. From there, holding a discussion about the Physical Education and Epistemology, based on authors of these areas, and as a summary, we support the important relationship between epistemology and pedagogical practice, we feel that this relationship helps teachers overcome the daily qualifying immediate his pedagogical practice.

KEYWORDS: Epistemology - Pedagogical Practice - School

Santa Maria (UFSM), em março de 2005 e apresenta um grupo de trabalho ${ }^{4}$ formado por acadêmicos de Educação Física, alunos do curso de especialização em Educação Física escolar e professores de Educação Física da rede pública municipal e estadual. O grupo é coordenado pela professora adjunta do Departamento de Desportos Individuais do CEFD, Maristela da Silva Souza.

Não vamos contar, aqui, a história do processo de elaboração da LEEDEFE, mas gostaríamos de salientar, que, hoje, o compromisso que a mesma assume frente à comunidade, é herdado de outros proje- 
tos, que em momentos anteriores desenvolveram-se no CEFD, como o projeto Universidade-Comunidade (PUNICOM), coordenado pela professora Dra Ingrid Marianne Baecker e o Projeto Criança Cidadã, também coordenado pela referida professora e, posteriormente, pelo professor, Ms Wilton Orlando Trapp. Portanto, a LEEDEFE representa, hoje, uma síntese do que foi coletivamente produzido em anos de trabalho, ao mesmo tempo que podemos considerá-la como mais um ponto de partida para novos saltos qualitativos rumo a uma produção de conhecimento comprometida com os interesses populares.

O objetivo da LEEDEFE consiste em criar um espaço para a construção do conhecimento da Educação Física escolarnos âmbitos do ensino, da pesquisa e da extensão, no sentido de aprofundar seus aspectos epistemológicos e didáticos. Para dar conta deste objetivo geral, a mesma apresenta, sistematizados em três eixos ${ }^{5}$, seus objetivos específicos, juntamente com suas ações. $\mathrm{Na}$ seqüência, iremos apresentar como a LEEDEFE vem desenvolvendo esses três eixos e contribuindo na construção do conhecimento da Educação Física escolar.

\section{$1^{\circ}$ e $2^{\circ}$ Eixos: intercâmbios e instrumentalização teórica}

No primeiro eixo, procuramos desenvolver ações que materializem intercâmbios com instituições de ensino e linhas de pesquisas, onde se encontra a realização, de dois em dois anos, do Seminário em epistemologia e Educação Física Escolar, que trouxe enquanto temática no ano de 2005 a questão: "Epistemologia e Prática Pedagógica: que relação é essa?" e no ano de 2007 a questão: "Conhecimento em Educação Física Escolar: No movimento das mudanças do mundo do trabaIho". Consideramos o espaço de intercâmbio, como de grande relevância para ampliarmos o debate que permeia a área da Educação Física, tendo em vista um trabalho de produção coletiva em torno de questões que afetam diretamente o ensino e a pesquisa em Educação Física escolar.

$$
\text { Partindo desta necessi- }
$$
dade concreta de produção e socialização de conhecimento, a LEEDEFE objetiva articular projetos de iniciação científica e projetos

5 Essa divisão em 3 eixos é apenas de cunho didático, já que buscamos garantir no desenvolvimento dos trabalhos uma articulação desses momentos. 
de pós-graduação ${ }^{6}$, com o fim de produzir e socializar conhecimentos através de publicações em periódicos e livros, atendendo ao contexto da comunicação científica, bem como, atendendo a necessidade histórica do Centro de Educação Física e Desportos, de reabrir o programa de pós-graduação em nível de mestrado e doutorado. Possibilitamos, também, ainda neste primeiro eixo, estabelecer trocas com os movimentos sociais, no sentido de firmar um horizonte histórico comprometido com os interesses populares, onde educação, ciência e tecnologia, exerçam um papel estratégico para este fim.

No segundo eixo, encontrase o objetivo de instrumentalizar acadêmicos e professores sobre as bases epistemológicas do conhecimento e sobre os parâmetros didáticos que orientam as práticas pedagógicas em Educação Física escolar.

No sentido de possibilitar esta instrumentalização, materializase a necessidade de compreender a relação dialética que ocorre entre epistemologia e prática pedagógica, tendo em vista que a intervenção pedagógica não se encontra indissociada do conhecimento oriundo do campo da ciência. Assim entendemos que tanto para a análise, quanto para a intervenção da Educação Física escolar, faz-se necessário, inseri-la no plano da produção do conhecimento científico. Isto se justifica por entendermos a Educação Física como área de conhecimento que trata da cultura corporal, produzida no processo histórico pelos sujeitos em movimento, portanto, resultante das manifestações sociais dos seres humanos, dentre essas, a ciência (Souza, 2004).

A nosso ver, a importância da Educação Física em entender os diferentes projetos científicos, consiste não somente em estabelecer como se pesquisa, mas compreender, que em um processo de ensino, os aspectos pedagógicos, expressam-se pelas opções científicas e pela maneira como estabelecemos a relação entre o conhecimento e a realidade. O campo de conhecimento da Educação Física se desenvolve na tensão entre estes diferentes projetos, o que resulta em uma determinada hegemonia.

Concordamos com Escobar (1997) quando esta afirma que a prática do professor necessita orientar-se no conhecimento aprofundado da luta ideológica contemporânea que, na área pedagógica, manifesta-se nas características que o sistema do

6 No caso do CEFD/UFSM temos, atualmente, na área pedagógica, o curso de especialização em Educação Física Escolar e ainda na discussão para a criação do mestrado, existe a proposta de uma linha de estudos e pesquisa que contemple a área pedagógica. 
livre movimento do capital impõe às atividades da escola, isolando-as dos problemas sociais que incrementam a contraposição dos interesses individuais aos sociais.

A autora salienta que essa leitura não indica que defendemos, como primeira tarefa, a mudança das consciências, pois o conteúdo da mudança alicerça-se no conhecimento científico concretizado numa nova prática não respaldada pelo senso comum. Uma prática dialética fundamenta-se no caminho da percepção ativa ao pensamento abstrato e desse à prática. Entretanto, a realidade hegemônica da prática pedagógica demonstra-nos que a distribuição do conhecimento exerce a manipulação do aluno pela informação e pelo condicionamento do seu comportamento e modos de pensar. Assim, faz-se necessário um projeto histórico/científico claro, para ajudar o professor a distinguir as ações necessárias para a formação de um determinado sujeito, para um determinado mundo do trabalho.

Entendemos que para o desenvolvimento de tal propósito, faz-se necessário estabelecer um diálogo, demonstrando a importância do campo da epistemologia para o alcance de uma prática pedagógica em Educação Física escolar qualitativamente alterada. Assim, antes de apresentarmos o terceiro eixo, iremos abrir uma discussão entre epistemolo- gia e prática pedagógica, no sentido de melhor justificar essa relação.

\section{Prática pedagógica e epistemo- logia: uma relação necessária}

Antes de tratarmos propriamente da relação dialética entre prática pedagógica e epistemologia, faz-se necessário historicizá-las, ou seja, compreendê-las no seu processo histórico de desenvolvimento. Para chegar a esse nível de compreensão, precisamos partir do conhecimento mais desenvolvido, que significa partir daquele que mais se aproxima da essência desses fenômenos. Em outras palavras, precisamos analisar o conhecimento que, enquanto reflexo da realidade objetiva no pensamento, apresenta o maior nível de fidelidade e precisão em relação ao seu objeto de estudo (Kopnin, 1978).

Primeiramente, no que se refere a conceitos, a prática pedagógica pode ser definida com base na concepção de ato educativo formulada por Saviani apud Duarte (1998 p. 85; 1999, prefácio):

(...) é o ato de produzir, direta e intencionalmente, em cada indivíduo singular, a humanidade que é produzida histórica e coletivamente pelo conjunto dos homens. Assim, o objeto da educação diz respeito, de um 
lado, à identificação dos elementos culturais que precisam ser assimilados pelos indivíduos da espécie humana para que eles se tornem humanos e, de outro lado e concomitantemente, à descoberta das formas mais adequadas para atingir esse objetivo.

No que se refere à epistemologia, esta é conceituada por Sánchez Gamboa (2002, p. 68) como o "estudo crítico dos princípios, das hipóteses e dos resultados das diversas ciências, destinado a determinar sua origem lógica (no psicológico), seu valor e seu alcance (...)". A epistemologia também faz a crítica aos diversos paradigmas, apontando para a superação de mitos e elaboração de novas metodologias. Segundo o autor, a "análise epistemológica situa-se como análise conceitual de segunda ordem que questiona os fundamentos das ciências, os processos de produção do conhecimento e os parâmetros de confiabilidade e veracidade (contexto da justificativa) da pesquisa científica (...)" (p. 68). A epistemologia busca seus princípios de análise na filosofia, e seu objeto de estudo nas práticas concretas das diversas ciências. Sua função é "abordar os problemas gerais das relações entre a filosofia e a ciência" (p. 69).

A partir disso, para expressarmos a importância da epistemo- logia para o contexto da Educação Física escolar, precisamos conhecer, ainda que brevemente (devido às limitações físicas deste trabalho), a história da Epistemologia, que abordaremos a partir dos estudos de Silva (1997).

Inicialmente, o termo Epistemologia com o significado literal de Teoria da Ciência, segundo a autora, só veio a surgir no vocabulário filosófico a partir do século XIX. A origem e utilização do termo Epistemologia, significando Teoria da Ciência, surge comprometida com a tradição positivista, que entende o conhecimento como as realizações da ciência, na medida em que reduz a Teoria do Conhecimento à Teoria do Conhecimento Científico. Até esse momento, já haviam surgido algumas obras que se aproximavam do que mais tarde veio a configurar-se como Epistemologia, mas, somente nesse século, são encontradas obras consideradas precursoras da Epistemologia, principalmente com Dugald Stwart, Auguste Conte e John Herschel.

Apesar dessas, somente no segundo terço do século XIX, surgem duas obras fundamentais para a construção do que se passou mais tarde a chamar-se de Epistemologia. Para Silva (1997), as referidas obras consistem na "Wissenschaftslehre" de Bernardo Bolzano (1837), com referência às ciências 
formais, lógica e matemática, e a "Philosofy of the inductive sciences" referente às ciências da natureza, de Wiliam Whewell (1840). De acordo com Silva (1997), o conceito de Wissenschaftslehre em Bernardo Bolzano (1837), designa propriamente o conhecimento científico, excluindo-se qualquer outra forma possível de conhecimento. Nesse sentido, a Epistemologia pode ser entendida como uma reflexão sobre a ciência, incluindo-se, dessa forma, na Metaciência (estudo que vem depois da ciência e que diz respeito a ela), onde a Teoria da Ciência ou Epistemologia determinam propriamente o conhecimento científico com a exclusão de qualquer outra forma possível de conhecimento.

Habermas, citado por Silva (1997), esclarece essa substituição da Teoria do Conhecimento pela Teoria da Ciência através do fato de que o sujeito não se apresenta mais como um sistema de referência, pois na Teoria da Ciência não se questiona sobre o sujeito que conhece e sim, trata as ciências disponíveis como um complexo de regras com base nas quais as teorias são edificadas e controladas.

Assim, Habermas analisa a redução da Teoria do Conhecimento à Teoria da Ciência e procura detectar, nas etapas teóricas dessa redução, a perda de uma reflexão sobre o entrelaçamento das ciên- cias com o processo histórico da sociedade. Para a superação desse reducionismo, Habermas propõe duas teses programáticas, ou seja: "A Teoria do Conhecimento como Teoria da Sociedade e da Evolução" e a "Teoria Dialética da Sociedade como reintrodução dos fenômenos epistemológicos do Materialismo Histórico" (Silva, 1997).

Essas duas teses, que procuram fazer um resgate do caráter crítico da Teoria do Conhecimento, fornecem as bases para uma reconstrução das relações entre Filosofia e Ciência. Habermas ainda destaca que a partir delas, será possível: reconquistar e reavaliar as dimensões da Teoria do Conhecimento, escamoteadas pela visão positivista; devolver às ciências a possibilidade de auto-reflexão e de entendimento de sua inserção na totalidade social; como, também, reintroduzir os fundamentos do materialismo histórico na reflexão sobre a ciência, no sentido de possibilitar o entendimento do conhecimento como uma produção humana mediatizada pelo desenvolvimento histórico da sociedade. A partir desse entendimento, a Epistemologia é compreendida como Teoria Crítica do Conhecimento que não se fecha no campo da ciência, mas torna-se uma crítica do conhecimento.

Portanto, como entendemos que o conhecimento que 
constitui uma pedagogia inclui processos sócioculturais, concepção psicológica de aluno, forma de organização de conteúdo, método de ensino, etc., e que esses processos formam uma pedagogia à medida que se encontram articulados por um pressuposto científico que contempla em seu interior uma concepção de mundo, de ser humano e de educação, é que acreditamos que o campo da epistemologia, enquanto Teoria Crítica do Conhecimento contribuirá fortemente para a tomada de consciência, por parte do educador, dos pressupostos que direcionam os seus atos educativos, no sentido de qualificar sua prática pedagógica. Tomar consciência exige estudo e reflexão e, nesse sentido, no caso do professor de Educação Física, explicitar a sua posição teórica possibilita uma meIhor orientação para superar os seus problemas específicos acumulados historicamente. Nessa direção, não intencionamos julgar os professores de Educação Física, mas refletir sobre as possibilidades de transformação que temos na nossa ação pedagógica, pois como nos declara Ilien (1999):

A pedagogia e com ela os pedagogos, necessita de credibilidade em seus objetivos. Que esta também tenha validade fora do âmbito pedagógico, que seja justificá- vel filosoficamente e, além disso, que esteja ancorada numa visão de mundo a partir de círculos populacionais maiores. A pedagogia depende, pois, do potencial utópico daquela sociedade que ela almeja tornar melhor através de sua atividade (p.132).

Tomado nesta perspectiva, o teorizar em Educação Física, em especial neste texto, através da pedagogia do movimento humano, assume o compromisso com a superação da imediaticidade cotidiana, apropriando-se das constantes variáveis dos fenômenos humanos ocorridos no contexto da escola, pois acreditamos que uma pedagogia deve estar sempre em "alerta crítico" no sentido de perceber os aspectos sociais que se encontram atrelados às mudanças históricas. As mediações exigidas pela pedagogia são bem mais complexas, estão além da sala de aula, do pátio ou dos muros da escola.

Hoje, estamos diante das "ditas" mudanças paradigmáticas que refletem diretamente no campo da educação, por ser este palco privilegiado de discussões sociológicas, filosóficas, etc. Por isso, a pedagogia e a pedagogia do movimento humano, deverão, segundo Souza (2004), estar atentas, desconfiar das objetivações propostas pela sociedade moderna que, em busca de superar 
este momento de crise, reestruturase. E a Educação Física, que como sempre foi "presa fácil" à ideologia moderna ${ }^{7}$, deverá alertar-se para não cair, mais uma vez, nas mazelas ideológicas do capitalismo, do qual o grito, agora, explicita-se "morte ao todo, viva a partícula" (RESENDE apud SOUZA, 2004, p.72).

Além dessas questões que afetam diretamente a prática pedagógica em Educação Física escolar, a epistemologia, como nos coloca Sánchez Gamboa (1994) apresenta outras questões susceptíveis de discussão. Neste sentido, o autor salienta o que denomina de "Colonialismo Epistemológico" das ciências mães, no qual "a Educação Física torna-se um campo colonizado onde são aplicados os métodos e as teorias dessas ciências, denominando-se, por exemplo, Psicologia da Aprendizagem Motora, Fisiologia do Esforço, etc" (p. 36).

A crítica dessa relação (Educação Física e ciências mães), ocorre pelo fato de que o ponto de partida e o ponto de chegada dos estudos da Educação Física são as ciências mães, sendo que ela funciona apenas como campo de passagem ou como laboratório para aquelas confirmarem suas hipóte- ses, em relação aos fenômenos da Educação Física.

Concordamos com Sánchez Gamboa (1994) quando este afirma que a superação desse "Colonialismo Epistemológico" exige revertermos o circuito do conhecimento, ou seja, devemos tomar "como ponto de partida e de chegada, a Educação Física, e como instrumental explicativo ou compreensivo, a contribuição teórica de outras disciplinas" (p.37).

A construção do conhecimento da Educação Física tem se apoiado em áreas multidisciplinares do conhecimento, ou seja, várias áreas de conhecimento atuando sobre o sujeito, sem concepções teóricas comuns. Para superar esta fragmentação de saberes, Kunz (1996) propõe sua transformação em um campo interdisciplinar, ou seja, que as várias áreas de conhecimentos científicos estabeleçam "uma unidade teórica em conceitos e categorias básicas: indivíduo, sociedade, aluno, ensino, educação, movimento, esporte, etc" (p.141). Para Silva (1997), especificamente no caso da Educação Física e esporte, não há como negar que nos últimos vinte anos vêm ocorrendo importantes mudanças que estão

7 Estudos como de Guiraldelli Junior (1988), Silva (1990, 1997), Bracht $(1992,1993)$ entre outros, apontam a Educação Física como área de conhecimento que se apresenta comprometida com a ideologia Natural/positivista dominante na sociedade capitalista. 
contribuindo para a construção de um perfil epistemológico novo para esta área de conhecimento, sendo que estas modificações são produto e processo de um contexto mais amplo, resultado de múltiplos determinantes histórico-sociais.

Portanto, entendemos, que o campo da epistemologia proporcionou à área da Educação Física grandes avanços no que trata de discussões teóricas, bem como o desenvolvimento de práticas pedagógicas comprometidas com o saber cultural elaborado da Educação Física escolar. Assim, a LEEDEFE compromete-se com a relação entre prática pedagógica em Educação Física escolar e epistemologia, acreditando ser essa uma relação necessária para orientar o desenvolvimento de uma prática pedagógica que apreenda o movimento das coisas tanto no âmbito dos saberes populares como das ciências humanas e naturais.

\section{$3^{\circ}$ Eixo: ações e pressuposto teórico da leedefe}

Neste último e terceiro eixo, encontra-se o objetivo de estabelecer um trabalho indissociável entre ensino, pesquisa e extensão numa relação dialética entre universidade e comunidade. Essa relação se materializa nas seguintes atividades desenvolvidas pela LEEDEFE:
GRUPOS DE ESTUDOS: A formação dos participantes da LEEDEFE consiste numa questão de extrema importância. Acreditamos ser, no processo de estudo, discussão e reflexão que nos apropriamos de instrumentos para darmos conta dos problemas e necessidades surgidas frente ao ato educativo e relações estabelecidas no contexto de ensino, bem como, das problemáticas de pesquisa e demais ações do grupo.

AULAS NAS COMUNIDADES: Constitui-se no momento de concretização de um dos objetivos da LEEDEFE, e possibilita o desenvolvimento de atividades nas comunidades no âmbito do ensino formal. Esta ação acontece no decorrer do processo de formação dos acadêmicos que participam da LEEDEFE, como também, no desenvolvimento dos estágios profissionalizantes que são orientados pela coordenadora da linha.

REUNIÕES PEDAGÓGICAS: Encontros semanais dos participantes com o coordenador da linha, com o fim de avaliar e planejar as atividades que são desenvolvidas junto à comunidade.

\section{ELABORAÇÃO DE ATIVIDADES} DE PESQUISA: Neste espaço, discutimos, avaliamos e elaboramos todas as ações voltadas à investigação, ou seja, dos alunos de graduação, 
pós-graduação (especialização em Educação Física Escolar).

SEMINÁRIOS DE APROFUNDAMENTO: A organização dos seminários de aprofundamento vem se desenvolvendo a partir das necessidades das diferentes ações realizadas pela LEEDEFE.

PARTICIPAÇÃO EM EVENTOS com o objetivo de expor os trabalhos desenvolvidos na LEEDEFE e dialogar com outros grupos de trabalho que produzem conhecimento no âmbito da epistemologia e da prática pedagógica em Educação Física Escolar.

Tais atividades são direcionadas pelo Materialismo Histórico e Dialético, que se constitui no pressuposto teórico de que a LEEDEFE se sustenta. Não pretendemos, aqui, aprofundar esse referencial teórico, apenas queremos apresentar, brevemente, sua lógica de apreensão do conhecimento, pois entendemos que compreender e conhecer os fenômenos enquanto síntese, ou seja, como totalidade, é uma tarefa difícil, pois como nos declara Marx (1983), há uma distinção entre a forma de manifestação das coisas e a sua real constituição, ou seja, há uma diferença entre a aparência e a essência dos fenômenos.

Neste sentido, Kopnin (1978) relata que na lógica dialética o pensamento é entendido como reflexo da realidade sob forma de abstrações. Assim, "o pensamento é um modo de conhecimento da realidade objetiva pelo homem" ( $p$. 121). No entanto, para o conhecimento se constituir num meio de assimilação prática dos processos e objetos, esse deve possuí-los em seu conteúdo, refletir as propriedades e leis da realidade objetiva, e não ver as coisas apenas tais quais são dadas na natureza, na sua aparência.

Para tanto, ANDERY et all (2003) relata que, para Marx, o estudo de qualquer fenômeno deve partir de sua realidade concreta, daquela na qual está inserido, compreendendo-o nela e não o abstraindo desta realidade: "parece que o correto é começar pelo real e pelo concreto" (Marx apud Andery, 2003, p. 415). Neste sentido, KOPNIN (1978) relata que o concreto, para a dialética materialista, é tanto o ponto de partida quanto o ponto de chegada do conhecimento, porém, esse "conhecimento não pode passar imediatamente do sensorial-concreto ao concreto no pensamento" (p. 158) e, sim, deve percorrer um trajeto complexo e contraditório através de abstrações, que são, como afirma Lênin (apud Kopnin, 1978, p. 159), o reflexo da "natureza com mais profundidade, mais fidelidade e mais plenitude" no pensamento. Por esse motivo, por meio das abstrações, o homem, 
através da ciência, é capaz de apreender aquilo que é inacessível à contemplação viva, ou seja, é capaz de apreender não apenas a aparência, mas também a essência das coisas.

Kopnin (1978) afirma que as abstrações são boas quando desvelam as leis reais da natureza e da sociedade, quando possibilitam ao homem o conhecimento dos processos profundos, inacessíveis à contemplação imediata, sensorial. Porém, se o pensamento se encerra em abstrações, deixa de ser meio de conhecimento da realidade e se transforma em instrumento para distanciar-se dela.

Assim, percebemos que a abstração também tem seu lado fraco, pois nela a realidade se simplifica, torna-se rudimentar, onde há um afastamento do objeto. É por perceber a necessidade das abstrações, bem como as limitações dessas, que o materialismo define as vias de superação dessas limitações, sendo elas "as vias de representação do movimento na abstração tal qual ela existe na realidade" (Kopnin, 1978, p. 161).

As abstrações, dessa forma, são apenas um meio para se chegar ao fim, sendo este fim, o fornecimento de um conhecimento concreto do objeto, um conhecimento novo, mais elevado. Por esse motivo, o concreto é, ao mesmo tempo, o ponto de partida e o de chegada, sendo que o concreto, enquanto ponto de partida, é o concreto-empírico e o concreto, enquanto ponto de chegada é o concreto-pensado, sendo esse último o processo de remontar, e não simplesmente o retorno ao ponto de partida, pois nesse processo se cria um novo concreto.

Podemos afirmar, portanto, que o processo de conhecimento, parte do concreto (real), passa por abstrações (o que envolve conceitos, categorias, etc...) e volta novamente ao concreto, só que agora de forma mais elaborada, pois se expressa como forma superior de conhecimento dos fenômenos da realidade, refletindo um novo nível de conteúdo mais elaborado (Silva, 1990). No entanto, devemos levar em consideração que o empírico e o abstrato são meros passos para nos apropriarmos, no plano do pensamento, do ponto principal que é o concreto.

Além disso,

o movimento do sensorial-concreto - através do abstrato - ao concreto, que reproduz o objeto no conjunto de abstrações, é uma manifestação da lei da negação da negação. O abstrato é a negação do sensorial-concreto. O concreto no pensamento é a negação do abstrato, mas o concreto mental não é a retomada 
do concreto inicial, mas o resultado da ascensão a um concreto novo, mais substancial (KOPNIN, 1978, p. 162).

Porém, precisamos ter a compreensão de que a ascensão do abstrato ao concreto não é uma soma de abstrações isoladas, que não dependem umas das outras, mas sim, que na construção do concreto, uma abstração surge como continuação lógica e contemplação da outra. Isso, na totalidade, "ocorre à base de uma idéia que traduz a lei fundamental no movimento do objeto" (Kopnin, 1978, p. 163).

Desse modo, a produção de conhecimento deve caminhar no sentido de desvendar as determinações, de modo algum transparentes no fenômeno. O sujeito do conhecimento tem, portanto, a tarefa de descobrir essas determinações. Essa descoberta acontece a partir da análise do fenômeno concreto (entendido este como ponto de partida), o qual será reconstruído no pensamento, isto é, reconstruído como concreto pensado.

A partir desta lógica de apreensão do saber, a LEEDEFE trata o processo de conhecimento da cultura corporal sob a sistematização metodológica proposta por Saviani (1997). Assim, a prática pedagógica inicia-se pela prática social (conhecimento caótico do todo), passando pelo momento da problematização (contradições), da instrumentalização (apropriação do conhecimento historicamente acumulado) e da catarse (totalidade - conhecimento mais elaborado), retornando à prática social (concreto pensado). Vale lembrar que esse é o caminho de ida e de volta, que se realiza através da dialética materialista.

\section{Palavras finais}

Através do contexto teórico, acima desenvolvido, procuramos esclarecer os nossos objetivos e as nossas concepções de conhecimento e de prática pedagógica que, juntas, e de maneira indissociadas, constituem a nossa visão de mundo, que, presente nas nossas ações, procura manter erguida a bandeira em defesa da Universidade Pública, Gratuita e de Qualidade.

Reafirmamos, nestas palavras finais, o compromisso de direcionarmos a produção de conhecimento em Educação Física Escolar numa perspectiva crítica e que, através do "tripé" ensino, pesquisa e extensão, possibilitamos o desenvolvimento de um conhecimento socialmente relevante aos interesses da população marginalizada de nosso país. Para isso, temos como meta buscar maior apoio junto aos órgãos de fomento à pesquisa, ensino e extensão, melhorando, assim, 
as condições para que a LEEDEFE atinja seus propósitos. Assim, a LEEDEFE coloca-se à disposição de todos que queiram compartilhar e contribuir com seus objetivos, bem como somar a estes, outros, que sejam comprometidos com valores de cunho, eminentemente, coletivos.

\section{Referências}

ANDERY, M. A.P.A. \& SÉRIO, T.M. P. A. A prática, a história e a construção do conhecimento: Karl Marx (1818-1883). In: Para compreender a ciência: uma perspectiva histórica. Rio de Janeiro: Espaço e tempo, 2003.

BRACHT, V. Educação Física e Aprendizagem Social. Porto Alegre: Magister,1992.

- Educação Física/Ciências do Esporte: que Ciência é essa? Revista Brasileira de Ciências do Esporte. 14(3), dez 1993, p. 111-118.

DUARTE, N. Concepções afirmativas e negativas sobre o ato de ensinar. In: Cadernos CEDES, v. 19, n. 44, abr 1998, p. $85-106$.

ESCOBAR, M. O. Transformação da Didática: construção da teoria pedagógica como categorias da prática pedagógica: experiência na disciplina escolar Educação Física. Tese de Doutorado.
Universidade Estadual de Campinas, Faculdade de Educação. Campinas, SP, 1997. GUIRALDELLI JR, P. Educação Física Progressista. A Pedagogia Crítico-Social dos Conteúdos e a Educação Física Brasileira. São Paulo: Loyola, 1988.

ILIEN, A. Desenvolvimento na realidade educacional e no pensamento educacional nas relações industriais ocidentais desenvolvidas, com ênfase especial na situação Alemã. In: Revista Brasileira de Ciências do Esporte. V. 20, no 2 e 3, abril a setembro, 1999.

KOPNIN, P. V. A dialética como teoria e lógica do conhecimento. Rio de Janeiro: Civilização Brasileira, 1978.

KUNZ, E. C i ência e interdisciplinariedade. In: Revista Brasileira de Ciências do Esporte, n 17 (2), jan 1996, p. $138-142$.

MARX, K. Contribuição à crítica da economia política. São Paulo: Martins Fontes, 1983.

SÁNCHEZ GAMBOA, S. S. Pesquisa em educação física: as inter-relações necessárias. In: Motrivivência, $n^{\circ}$ 5, 6 e 7, dez 1994, p. $34-46$.

- Pesquisa educacional: Quantidade-Qualidade. São Paulo: Cortez, 2002. 
SAVIANI, D. Escola e democracia. Tese de doutorado. Campinas: São Paulo: Cortez/Autores Associados, 1997.

SILVA, R. V. de S. Mestrados em educação física no Brasil: pesquisando suas pesquisas. Dissertação de mestrado. Santa Maria: UFSM, 1990. Unicamp, 1997.

SOUZA, M.S. Conhecimento teórico pedagógico em Esporte escolar: Possibilidade Superadora no plano da cultura corporal. Tese de doutorado. Santa Maria, CEFD/UFSM, 2004. - Pesquisa em educação física: determinações históricas e implicações epistemológicas.

Recebido: 30/agosto/2009

Aprovado: 30/outubro/2009 